***Reprinted with permission. No further reproduction is authorized without written permission from the American Real Estate Society. This version of the document is not the version of record. Figures and/or pictures may be missing from this format of the document.***

\title{
Retail Vacancy Rates: The Influence of National and Local Economic Conditions
}

Executive Summary. This study examines the extent to which local retail vacancy rates are influenced by vacancy rates in surrounding communities versus the overall national vacancy rate in the retail sector. Consistent with prior research, our simultaneous spatial autoregressive analyses of pooled retail market vacancy rates suggests that there is considerable spatial correlation in vacancy rates among neighboring metropolitan areas. There is also evidence of substantial temporal correlation in local vacancy rates. While spatial correlation dominates the national vacancy rate in explaining variation in the level of vacancy rates, changes in the national vacancy rate explain a statistically significant portion of the variation in the changes in local vacancy rates. The nature and extent to which changes in national rates affect local rates is found to differ markedly across MSAs.

*The American University, Washington, DC 20016 or jbenjeam.edu.

** University of North Carolina-Greensboro, Greensboro, NC 27412 or juddon@uncg.edu.

** * University of North Carolina-Greensboro, Greensboro. NC 27412 or dt_winkler@uncg.edu.

\author{
by John D. Benjamin* \\ G. Donald Jud** \\ Daniel T. Winkler***
}

\section{Introduction}

It is often said that "all real estate markets are local." But how strongly do national market conditions influence the performance of local property markets? This question is important to lenders, planners, developers, real estate investment trust portfolio managers and others who make or analyze real estate investment and portfolio decisions. Research by Hanink (1996) examines this question using office market data, finding that regional market conditions have a much stronger influence on local office markets than do conditions in the overall national market. Eppli, Shilling and Vandell (1996) provide similar findings. They report that very little of the variation in retail property returns are explained by contemporaneous macroeconomic events.

This study examines how local vacancy rates in the retail market are influenced by national market conditions. Our data track the retail real estate sector in forty-six metropolitan markets from 1981 through the first quarter of 1996 . The next sections discuss the theoretical background, the pooled retail data, the empirical methodology and the empirical results. The final section is the conclusion.

\section{Theoretical Background}

Retail markets traditionally have been considered to be primarily local in nature because retail market sizes and business volumes are derived from local economic and demographic conditions (DiPasquale and Wheaton, 1996). However, national 
economic conditions may also affect the demand for products produced by export-based industries located in a local area and thereby may affect the level of employment, income and local-market retail demand. Further, national credit market conditions may influence the cost and availability of capital and credit in a local area and thereby may influence the pace of new retail construction.

Because real estate markets (including retail) have a strong local orientation, they do not move in perfect accord with aggregate national market conditions. Regional diversification has been shown to reduce the level of unsystematic risk in real estate portfolios (for example, Hartzell, Shulman and Wurtzebach, 1987; Malizia and Simons, 1991; and Mueller, 1993). ${ }^{1}$ Research in this area has focused on the formulation of portfolio diversification strategies among geographic areas, property types and industrial sectors. Mueller (1993) tests a number of these strategies and concludes that diversifying along purely economic-base lines provides the best efficient frontier. Mueller's work suggests that the dominant employment base of an area drives local economic conditions and that real estate returns follow local market conditions. Nevertheless, national economic conditions may yet influence local markets (as Mueller acknowledges) through their effects on the levels of income and employment in the dominant economic-base industry and the effects of national credit-market conditions on the supply of local market space.

Hanink (1996) examines quarterly movements of the office market vacancy rates in thirty-one metropolitan markets using a mixed spatial autoregression analysis. His analysis suggests that local office markets are much more strongly affected by economic conditions in the surrounding region than in the overall national market. This relationship is an important issue because portfolio diversification strategies assume the existence of regional markets that move somewhat independently from trends in the overall national market. Thus, Hanink's findings support the application of regional diversification strategies in the construction and management of office market real estate portfolios. This article extends Hanink's analysis to retail markets, and extends the analysis from examining the levels of vacancy rates to changes in vacancy rates. The sections that follow report the results of simultaneous spatial autoregressive analyses of pooled retail market vacancy rates.

\section{Data}

We examine quarterly data for forty-six metropolitan statistical areas (MSAs) from 1982:1 to 1996:1. The retail vacancy rate data reflect the interaction of demand and supply forces in fortysix metropolitan retail markets. The data set consists of 2,622 observations. The vacancy rate data, obtained from F. W. Dodge, cover the aggregate number of square feet of retail space in each market, excluding restaurants.

Exhibit 1 shows descriptive statistics of average local vacancy rates (LVRs) for 46 MSAs by quarter, extending from the first quarter of 1982 through the first quarter of 1996 . The lowest vacancy rates appeared during 1983-84, while the highest occurred during 1991-92. The higher vacancy rates during the early 1990 s coincide with higher standard deviations of the vacancy rates, as shown in Exhibit 2. The normalized local vacancy rate, defined as the mean vacancy rate divided by the standard deviation, appears to have slowly drifted upwards since the early to mid-1980s.

Exhibit 3 shows a summary of the data. Over the fifty-four quarter time interval, the average or mean LVR is $8.39 \%$, with a range from $0.68 \%$ to $25.21 \%$. The average national vacancy rate (NVR) is $7.96 \%$, and ranges from $4.60 \%$ to $11.15 \%$. Likewise, the standard deviation for the NVR is substantially less at $1.68 \%$ versus $4.28 \%$ for the LVRs. First differences indicate that although average quarterly changes are usually small, the variation can be substantial.

\section{Methodology}

The effect of the NVR on LVRs is measured first using a fixed effects model. We assume initially that the level of the vacancy rate for each of the $M$ MSAs is determined by the NVR and by influences specific to each MSA, which are captured by a structural variable for each MSA as follows: 


\section{Exhibit 1}

Average Local Retall Vacancy Rates from 1982:4 through 1996:1 for Forty-Six MSAs

\begin{tabular}{|c|c|c|c|c|c|}
\hline Year:Ouarter & Mean & Std. Dev & $\begin{array}{l}\text { Normalized } \\
\text { Variation }\end{array}$ & $\begin{array}{l}\text { Maximum } \\
\text { LVR }\end{array}$ & $\begin{array}{l}\text { Minimum } \\
\text { LVR }\end{array}$ \\
\hline $1982: 1$ & 6.65 & 2.96 & 2.25 & 16.14 & 2.02 \\
\hline $1982: 2$ & 6.86 & 3.00 & 2.29 & 15.54 & 2.36 \\
\hline $1982: 3$ & 6.93 & 3.15 & 2.20 & 15.25 & 2.74 \\
\hline $1982: 4$ & 7.54 & 3.15 & 2.39 & 15.16 & 2.59 \\
\hline $1983: 1$ & 7.23 & 3.19 & 2.27 & 16.08 & 2.58 \\
\hline 1983:2 & 6.38 & 3.07 & 2.08 & 15.66 & 2.10 \\
\hline 1983:3 & 5.35 & 2.88 & 1.86 & 15.40 & 0.74 \\
\hline $1983: 4$ & 5.27 & 2.97 & 1.77 & 15.15 & 0.68 \\
\hline $1984: 1$ & 5.02 & 2.74 & 1.83 & 14.99 & 0.83 \\
\hline $1984: 2$ & 5.25 & 2.76 & 1.90 & 14.43 & 1.42 \\
\hline $1984: 3$ & 5.67 & 2.82 & 2.01 & 13.62 & 1.46 \\
\hline $1984: 4$ & 6.12 & 3.04 & 2.01 & 13.49 & 1.72 \\
\hline 1985:1 & 6.56 & 3.63 & 1.81 & 17.86 & 1.86 \\
\hline $1985: 2$ & 6.65 & 3.57 & 1.86 & 17.43 & 1.93 \\
\hline $1985: 3$ & 7.04 & 4.02 & 1.75 & 18.40 & 1.46 \\
\hline $1985: 4$ & 7.10 & 3.94 & 1.80 & 17.81 & 1.75 \\
\hline 1986:1 & 7.29 & 3.79 & 1.92 & 17.93 & 2.00 \\
\hline $1986: 2$ & 8.06 & 4.81 & 1.68 & 21.82 & 2.83 \\
\hline $1986: 3$ & 8.41 & 4.97 & 1.69 & 21.91 & 3.02 \\
\hline $1986: 4$ & 8.62 & 5.15 & 1.67 & 23.30 & 2.72 \\
\hline 1987:1 & 8.70 & 4.70 & 1.85 & 21.35 & 2.56 \\
\hline $1987: 2$ & 8.45 & 4.63 & 1.83 & 21.48 & 2.46 \\
\hline $1987: 3$ & 8.40 & 4.75 & 1.77 & 21.85 & 2.14 \\
\hline $1987: 4$ & 8.30 & 4.17 & 1.99 & 20.18 & 3.05 \\
\hline 1988:1 & 8.93 & 5.41 & 1.65 & 25.21 & 2.77 \\
\hline 1988:2 & 8.8 & 4.69 & 1.88 & 21.04 & 2.61 \\
\hline 1988:3 & 8.83 & 4.51 & 1.96 & 19.98 & 3.09 \\
\hline $1988: 4$ & 8.99 & 4.69 & 1.92 & 20.79 & 3.12 \\
\hline 1989:1 & 9.16 & 4.62 & 1.98 & 20.63 & 3.08 \\
\hline $1989: 2$ & 9.91 & 4.65 & 2.13 & 21.57 & 2.96 \\
\hline 1989:3 & 9.93 & 5.36 & 1.85 & 24.91 & 3.25 \\
\hline 1989:4 & 10.00 & 4.56 & 2.19 & 21.82 & 3.56 \\
\hline 1990:1 & 9.16 & 3.92 & 2.34 & 19.09 & 3.77 \\
\hline $1990: 2$ & 9.87 & 4.64 & 2.13 & 22.87 & 4.29 \\
\hline $1990: 3$ & 10.43 & 4.84 & 2.15 & 23.37 & 4.84 \\
\hline 1990:4 & 11.28 & 4.79 & 2.35 & 22.72 & 5.21 \\
\hline $1991: 1$ & 11.32 & 3.94 & 2.87 & 21.35 & 5.53 \\
\hline $1991: 2$ & 11.35 & 4.12 & 2.75 & 22.51 & 6.80 \\
\hline $1991: 3$ & 11.22 & 4.65 & 2.41 & 23.42 & 6.12 \\
\hline $1991: 4$ & 11.23 & 5.23 & 2.15 & 23.96 & 5.52 \\
\hline 1992:1 & 11.45 & 4.96 & 2.31 & 23.78 & 5.80 \\
\hline $1992: 2$ & 11.11 & 4.51 & 2.46 & 22.27 & 5.45 \\
\hline $1992: 3$ & 10.61 & 3.82 & 2.78 & 19.71 & 6.12 \\
\hline $1992: 4$ & 9.95 & 3.81 & 2.61 & 20.08 & 5.66 \\
\hline 1993:1 & 9.32 & 3.74 & 2.49 & 19.69 & 4.08 \\
\hline 1993:2 & 8.86 & 3.54 & 2.50 & 17.57 & 2.75 \\
\hline 1993:3 & 8.74 & 3.69 & 2.37 & 17.32 & 3.39 \\
\hline 1993:4 & 8.76 & 3.47 & 2.52 & 16.27 & 3.18 \\
\hline 1994:1 & 8.68 & 3.32 & 2.61 & 16.05 & 3.63 \\
\hline 1994:2 & 8.33 & 3.26 & 2.56 & 14.94 & 3.06 \\
\hline $1994: 3$ & 8.08 & 3.09 & 2.61 & 14.56 & 2.84 \\
\hline $1994: 4$ & 7.51 & 2.94 & 2.55 & 12.75 & 2.66 \\
\hline $1995: 1$ & 6.72 & 2.54 & 2.65 & 11.40 & 2.48 \\
\hline 1995:2 & 7.69 & 2.83 & 2.72 & 13.55 & 3.32 \\
\hline $1995: 3$ & 7.75 & 3.17 & 2.44 & 14.70 & 3.24 \\
\hline $1995: 4$ & 8.18 & 3.18 & 2.57 & 14.46 & 3.28 \\
\hline $1996: 1$ & 8.32 & 3.30 & 2.52 & 14.92 & 3.15 \\
\hline
\end{tabular}




$$
L V R_{i t}=b_{0}+b_{1} N V R_{t}+\sum_{i=2}^{M} b_{i} M S A_{i t}+\varepsilon_{i t}
$$

where:

$L V R_{i t}=$ The LVR of MSA $i$ in quarter $t$ $N V R_{t}=$ The NVR in quarter $t$; and $M S A_{i t}=$ An indicator variable for MSA $i$ in quarter $t$

The coefficients $b_{0}, b_{1}$ and $b_{i}$ represent the regression parameters, and $\varepsilon_{i t}$ is the regression error term. This model estimates a common NVR coefficient with shifts in the intercept of the regression equation for different MSAs. The nature of timeseries cross-sectional vacancy rates suggests potential for autocorrelated disturbances. ${ }^{2}$ Therefore, a time-series autocorrelation component is utilized to measure and remove the effects of an autocorrelated error structure for each MSA as follows: ${ }^{3}$

$$
\varepsilon_{i t}=\rho_{i}^{T} \varepsilon_{i, t-1}+\nu_{i t}
$$

In this equation, $\rho_{i}^{T}$ is the time-series autocorrelation coefficient and $\nu_{i t}$ is the error term.

Hanink (1996) reports that a strong spatial autoregressive component exists in LVRs of office space, using a mixed spatial autoregressive model. 4 The following generalized simultaneous autoregressive model (SAR) examines spatial autoregressive tendencies for the retail market: ${ }^{5}$

$$
\mathbf{Y}_{\mathbf{L V R}}=\rho^{S} \mathbf{W} \mathbf{Y}_{\mathbf{L V R}}+\left(\mathbf{I}-\rho^{S} \mathbf{W}\right) \mathbf{X}_{\mathrm{NVR}} \mathbf{B}+\varepsilon
$$

where:

$\mathbf{Y}_{\mathbf{L V R}}=$ The vector of LVRs;

$\mathbf{X}_{\text {NVR }}=$ The vector of NVRs including structural time variables and a vector of ones for the intercept term;

$\mathbf{W}=$ The spatial weighting matrix based on the Delaunay triangularization method;

$\mathbf{I}=$ The identity matrix; and

$\mathbf{B}=$ The matrix of regression coefficients.

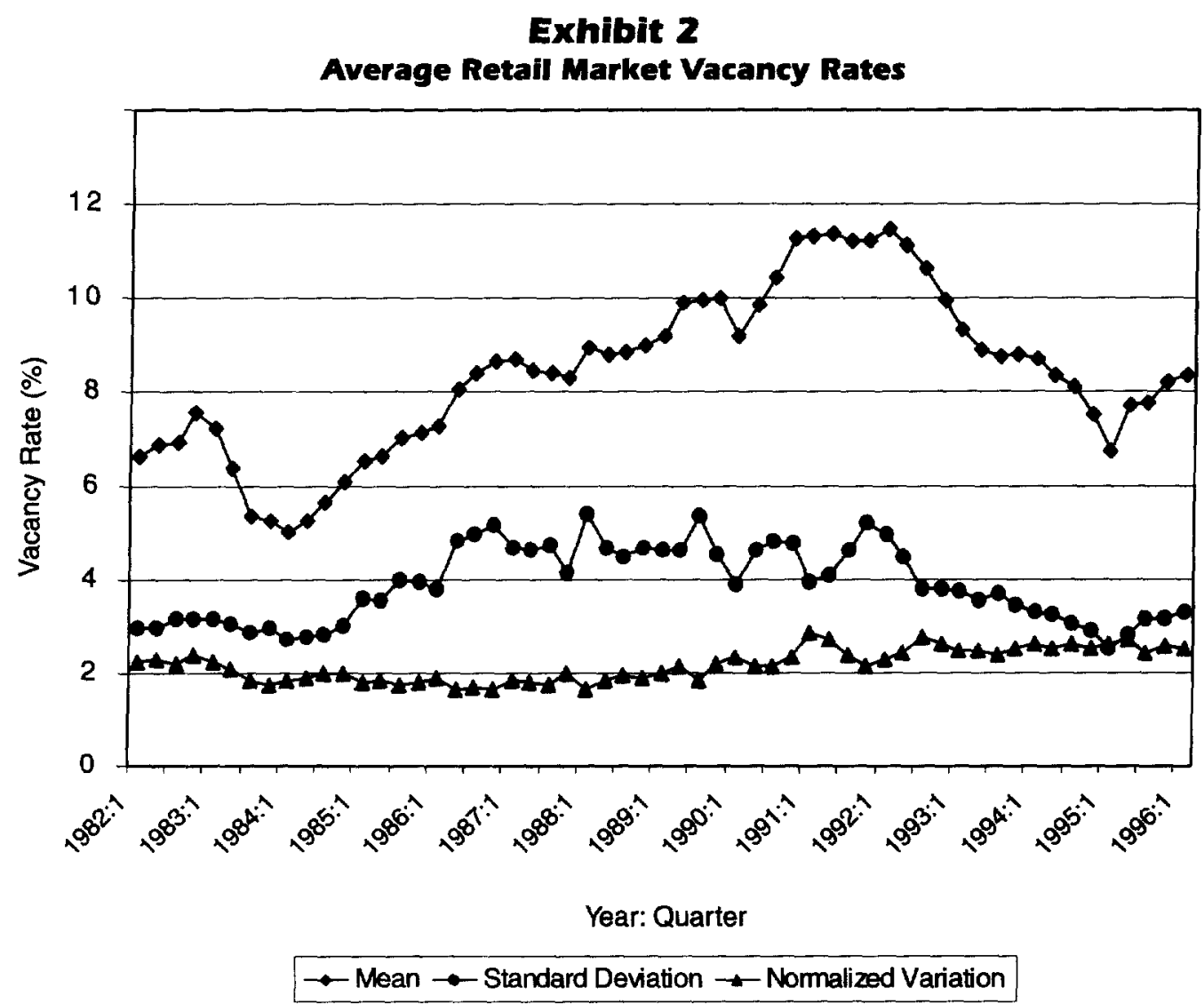


Exhibit 3

Descriptive Statistics

\begin{tabular}{lllll}
\hline Variable & Mean & Std. Dev. & Min. & Max. \\
\hline LVR & 8.39 & 4.28 & 0.68 & 25.21 \\
NVR & 7.96 & 1.68 & 4.60 & 11.15 \\
LVR $t-L V R_{t-1}$ & 0.03 & 1.22 & -5.66 & 6.51 \\
\hline
\end{tabular}

The coefficient $\rho^{S}$ is the spatial autoregressive parameter and $\varepsilon$ is the error term. The average values of vacancy rates in the surrounding MSAs, scaled by $\rho^{S}$ are subtracted from each observation similar to a time-series autocorrelation adjustment. The simultaneous autoregressive model has an unbiased ordinary least squares coefficient matrix, a relatively simple asymptotic covariance submatrix for the coefficient matrix, and an autoregressive error distribution (Griffith, 1993). Note that the autoregressive response model is the SAR model with the $\rho^{S} \mathbf{W X}_{\mathrm{NVR}} \mathbf{B}$ term removed. Therefore, the autoregressive response model is the simpler specification, positing a direct interdependence of LVRs on surrounding vacancy rates in addition to the influence of the NVR on the LVR (Griffith, 1993). The spatial autocorrelation coefficient is bounded by $0<\rho^{s}<1$ and can be interpreted as a measure of the extent to which LVRs are correlated with surrounding LVRs.

The third model is a first-differences approach that focuses on explaining the changes in LVRs instead of the levels of the vacancy rates. This approach is probably more useful for determining the influence of the NVR on LVRs because it focuses on explaining variation in LVRs. ${ }^{6}$ Moreover, the response of LVRs to NVRs may not be constant across MSAs; consequently, a separate-slopes model is tested to capture differential effects. This model is shown as follows:

$$
\begin{aligned}
L V R_{i t} & -L V R_{i, t-1}=d_{0}+\sum_{i=1}^{M-1} d_{i} M S A_{i t} \\
+ & \sum_{i=M}^{2 M-1} d_{i} M S A_{i t}\left(N V R_{t}-N V R_{t-1}\right)+\varepsilon_{i t}
\end{aligned}
$$

where:

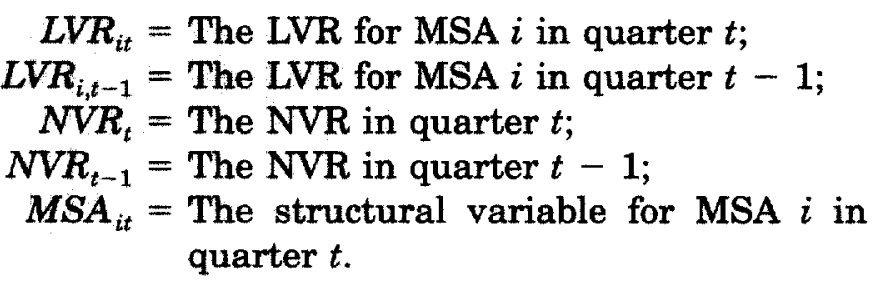

The regression parameters are $d_{i}$ and the error term is $\varepsilon_{i t}$. The term on the left-hand side of Equation (3) denotes the first differencing, the second term on the right-hand side denotes the structural variables for the MSAs, and the third term denotes the interaction variables for separate slopes. ${ }^{7}$ The next section utilizes this first-differencing approach as well as the two aforementioned approaches to examine the relationships between NVRs and LVRs.

\section{Empirical Results}

\section{Temporal Autocorrelation}

Exhibit 4 reports the empirical findings of a fixedeffects regression (Equation (1)) relating the LVRs to the NVR. As shown in the two far right columns, the autocorrelation coefficients are statistically significantly different from zero at .01 or more; therefore, the regression coefficients are reported using the Cochrane-Orcutt AR(1) correction procedure for each MSA, which reduces the number of observations by one for each MSA (Greene, 1997), ${ }^{8}$ The AR(1) terms range from 0.44 to 1.00 with a mean of 0.83 . Therefore, this range indicates that time-series autocorrelation is a large problem in the data, and the regression estimates will be inefficient with OLS (Greene, 1997).

The NVR coefficient is close to 1.0 , suggesting a corresponding one-to-one responsiveness of the LVR to changes in the NVR. Of the forty-six structural MSA variables, twenty are statistically significant. Of notable magnitude are the large positive MSA structural variables for cities in Texas, suggesting a concentration of high vacancy rates, as compared with California where the vacancy rates appear substantially less than the mean vacancy rate. The group dummies with the individual MSA adjustment for AR(1) collectively improve the explained variation to near 0.94 . The explained 
Exhibit 4

Fixed-Effects Retail Space Vacancy Regression with AR(1) Correction

\begin{tabular}{|c|c|c|c|c|}
\hline Variable & $\begin{array}{l}\text { Regression } \\
\text { Coefficient }\end{array}$ & $t$-Stat. & $\begin{array}{l}\text { Autocorrelation } \\
\text { Coefficient }\left(\rho^{T}\right)\end{array}$ & $t$-Stat. \\
\hline NVR & 0.989 & 22.80 & - & - \\
\hline Atlanta, GA & -0.343 & -0.57 & 0.714 & 5.37 \\
\hline Austin-San Marco, TX & 9.415 & 3.39 & 0.895 & 17.90 \\
\hline Birmingham, AL. & -2.937 & -4.68 & 0.818 & 11.97 \\
\hline Boston-Brockton, MA & -4.033 & -9.50 & 0.615 & 6.16 \\
\hline Chicago, IL & 0.161 & 0.37 & 0.509 & 5.54 \\
\hline Cincinnati, OH-KY-IN & -2.016 & -2.22 & 0.869 & 13.99 \\
\hline Columbus, $\mathrm{OH}$ & -1.827 & -1.41 & 0.869 & 18.21 \\
\hline Dallas, TX & 7.294 & 3.62 & 0.886 & 20.16 \\
\hline Denver, CO & 5.457 & 3.36 & 0.865 & 15.67 \\
\hline Detroit, MI & -2.817 & -4.22 & 0.844 & 11.85 \\
\hline Fort Lauderdale, FL & 1.784 & 0.90 & 0.890 & 14.70 \\
\hline Fort Fort-Arlington, $\mathrm{DX}$ & 8. 104 & 3.22 & 0.898 & 20.93 \\
\hline Greenville-Spartanburg-Anderson, SC & 2.384 & 2.58 & 0.897 & 21.19 \\
\hline Hartford. CT & -10.234 & -0.39 & 1.011 & 27.63 \\
\hline Honolulu, HI & -2.555 & -0.70 & 0.960 & 40.39 \\
\hline Houston, TX & 10.168 & 5.35 & 0.881 & 24.98 \\
\hline Indianapolis, IN & -1.870 & -1.47 & 0.909 & 15.18 \\
\hline Jacksonville, FL & 3.851 & 5.94 & 0.655 & 6.66 \\
\hline Kansas City, MO-KS & -0.888 & -1.32 & 0.816 & 10.79 \\
\hline Los Angeles-Long Beach, CA & -2.896 & -4.24 & 0.770 & 10.16 \\
\hline Miami, FL & -0.819 & -0.51 & 0.907 & 15.70 \\
\hline Milwaukee-Waukesha, W/ & 4.685 & 0.41 & 0.981 & 24.22 \\
\hline Minneapolis-St. Paul, MN-WI & -0.614 & -1.39 & 0.501 & 3.91 \\
\hline Nashville. TN & 0.747 & 0.46 & 0.896 & 15.80 \\
\hline Nassau-Suffolk, NY & -0.136 & -0.06 & 0.970 & 30.15 \\
\hline New Orleans, LA & 2.270 & 1.84 & 0.862 & 16.25 \\
\hline Oakland, CA & -1.272 & -2.49 & 0.723 & 8.33 \\
\hline Oklahoma City, OK & 4.944 & 5.18 & 0.706 & 7.21 \\
\hline Orange County, CA & -2.869 & -3.95 & 0.875 & 13.12 \\
\hline Orlando, FL & -0.597 & -1.43 & 0.437 & 3.37 \\
\hline Philadelphia, PA-NU & -1.024 & -1.14 & 0.889 & 14.12 \\
\hline Phoenix-Mesa, AZ & 3.151 & 2.88 & 0.804 & 10.75 \\
\hline Pittsburgh, PA & -1.523 & -2.93 & 0.748 & 7.65 \\
\hline Portland-Vancouver, OR-WA & -6.265 & -1.47 & 0.969 & 39.54 \\
\hline Raleigh-Durham-Chapel Hill, NC & -0.581 & -0.38 & 0.860 & 12.34 \\
\hline Richmond-Petersburg. VA & -1.365 & -1.53 & 0.841 & 11.35 \\
\hline Sacramento, CA & 0.975 & 1.38 & 0.748 & 8.79 \\
\hline St. Louis, MO-IL & -0.526 & -0.29 & 0.935 & 20.49 \\
\hline San Antonio, TX & 6.784 & 5.70 & 0.793 & 13.00 \\
\hline San Diego, CA & -0.699 & -0.41 & 0.916 & 15.67 \\
\hline San Francisco, CA & -3.664 & -9.10 & 0.686 & 7.05 \\
\hline San Jose, CA & -2.708 & -4.38 & 0.810 & 9.96 \\
\hline Seattle-Bellevue-Everett, WA & -2.867 & -1.79 & 0.938 & 29.44 \\
\hline Tampa-St. Petersburg-Clearwater, FL & 0.656 & 1.27 & 0.601 & 5.17 \\
\hline Tulsa, OK & 1.727 & 0.44 & 0.975 & 33.38 \\
\hline West Palm Beach-Boca Raton, FL & 1.989 & 3.30 & 0.596 & 4.78 \\
\hline
\end{tabular}

Note: $R^{2}=.9371$ and the F-Statistic $=401.92$.

variation using OLS, without the MSA dummy variables, but including autocorrelation correction, is only 0.15 . Therefore, while the $N V R$ coefficient is an important variable, there is strong evidence that individual MSA influences have an important role in the determination of the LVR.

\section{Spatial Autocorrelation}

The spatial regression are shown in Exhibit 5; it reports the vacancy model with and without time structural variables and reports the spatial autoregressive response and SAR model specifications. ${ }^{9}$ 
Exhibit 5

Retall Space Vacancy Regression Using Spatial Autocorrelation Models

\begin{tabular}{|c|c|c|c|c|}
\hline \multirow[b]{2}{*}{ Variables } & \multicolumn{2}{|c|}{ Autogregressive Response Model } & \multicolumn{2}{|c|}{ Simultaneous Autoregressive Model } \\
\hline & $\begin{array}{l}\text { W/O Time } \\
\text { Variables }\end{array}$ & $\begin{array}{l}\text { With Time } \\
\text { Variables }\end{array}$ & $\begin{array}{l}\text { W/O Time } \\
\text { Variables }\end{array}$ & $\begin{array}{l}\text { With Time } \\
\text { Variables }\end{array}$ \\
\hline Intercept & $\begin{array}{c}-5.469 \\
(3.683)\end{array}$ & $\begin{array}{r}-3.520 \\
(0.061)\end{array}$ & $\begin{array}{c}0.47 \\
(2.288)\end{array}$ & $\begin{array}{c}0.350 \\
(0.001)\end{array}$ \\
\hline NVR & $\begin{array}{c}1.025 \\
(785.795)\end{array}$ & $\begin{array}{c}0.624 \\
|0.089|\end{array}$ & $\begin{array}{c}0.998 \\
(844.720)\end{array}$ & $\begin{array}{c}0.942 \\
|0.233|\end{array}$ \\
\hline$\rho^{5}$ & 0.68 & 0.71 & 0.71 & 0.74 \\
\hline LR (Model) & $-13,251$ & $-13,142$ & $-13,221$ & $-13,113$ \\
\hline
\end{tabular}

Note: Time structural variables are not reported to conserve space. None are statistically significant at 0.10 or higher. Likelihood ratios are in parentheses.

Exhibit 6

Regression Models Using First Differences of Vacancy Rates

\begin{tabular}{|c|c|c|c|c|}
\hline Variable & $\begin{array}{l}\text { OLS } \\
\text { Regression }\end{array}$ & $\begin{array}{l}\text { Fixed-Effects } \\
\text { Regression }\end{array}$ & $\begin{array}{l}\text { Lagged NVR } \\
\text { Regression }\end{array}$ & $\begin{array}{l}\text { Simultaneous } \\
\text { Autoregressive Model }\end{array}$ \\
\hline Intercept & $\begin{array}{c}0.012 \\
(0.534)\end{array}$ & - & $\begin{array}{c}0.014 \\
(0.580)\end{array}$ & $\begin{array}{c}0.012 \\
{[0.285]}\end{array}$ \\
\hline$N V R_{t}-N V R_{t-1}$ & $\begin{array}{r}0.946 \\
(18.384)\end{array}$ & $\begin{array}{r}0.946 \\
(18.278\}\end{array}$ & $\begin{array}{r}0.942 \\
(16.44)\end{array}$ & $\begin{array}{r}0.946 \\
{[317.796]}\end{array}$ \\
\hline$N V R_{t-1}-N V R_{t-2}$ & - & - & $\begin{array}{c}0.008 \\
(0.128)\end{array}$ & - \\
\hline$N V R_{t-2}-N V R_{t-3}$ & - & - & $\begin{array}{c}0.014 \\
(0.237)\end{array}$ & - \\
\hline F-Value [Groups] & - & 0.26 & - & - \\
\hline Mean $\rho^{r}$ & - & -0.14 & - & - \\
\hline Mean $\rho^{s}$ & - & - & - & 0 \\
\hline$R^{2}$ & 0.11 & 0.12 & 0.12 & - \\
\hline F-Value (Model) & 337.97 & 7.50 & 110.02 & - \\
\hline LR (Model) & $-4,008.16$ & $-4,002.28$ & $-3,889.89$ & -10.468 .92 \\
\hline
\end{tabular}

Note: $t$-Statistics are in parentheses and log-likelihood ratios are in brackets.

All models require the use of maximum likelihood estimation. The model log-likelihood ratio is statistically significant in all cases. The spatial autoregressive coefficients range from 0.68 to 0.74 , indicating a substantial spatial autocorrelation. ${ }^{10}$ Using the time structural variables in the same regression with the NVR, however, creates a near singular matrix because the NVR is invariant among the MSAs. Greene (1997) identifies symptoms of multicollinearity including small changes in data that produce wide changes in the parameter estimates, very high standard errors and low significance levels (although joint significance of the regressors is high) as well as coefficients having the wrong sign or an implausible magnitude. These problems are manifested in our vacancy regression models that use time structural variables together with the NVR.

Using a similar spatial model with time structural variables, Hanink (1996) reports that the statistical nonsignificance of the NVR in the spatial model, together with the high statistical significance of the spatial autoregressive parameter (measuring the regional influence), provide strong evidence of a regional instead of a NVR effect. ${ }^{11}$ 
Exhibit 7

First Differences Regression with Separate Slopes by MSA

\begin{tabular}{|c|c|c|}
\hline Variable & $\begin{array}{l}\text { Regression } \\
\text { Coefficient }\end{array}$ & t-Stat. \\
\hline Intercept & 0.037 & 0.25 \\
\hline$\left(N V R_{t}-N V R_{t-1}\right) *$ Atlanta, GA & 1.788 & 5.17 \\
\hline$\left(N V R_{\mathrm{r}}-N V R_{t-1}\right) *$ Austin-San Marco, $\mathrm{TX}$ & 1.339 & 3.87 \\
\hline$\left(N V R_{\mathrm{r}}-N V R_{t-1}\right) *$ Birmingham, AL & 0.419 & 1.21 \\
\hline$\left(N V R_{t}-N V R_{t-1}\right) *$ Boston-Brockton, $M A$ & 0.543 & 1.57 \\
\hline$\left(N V R_{t}-N V R_{t-1}\right) *$ Chicago, IL & 0.936 & 2.71 \\
\hline$\left(N V R_{t}-N V R_{t-1}\right) *$ Cincinnati, OH-KY-IN & 1.199 & 3.47 \\
\hline$\left(N V R_{t}-N V R_{t-1}\right) *$ Columbus, $\mathrm{OH}$ & 1.011 & 2.93 \\
\hline$\left(N V R_{t}-N V R_{t-1}\right) *$ Dallas, TX & 1.754 & 5.07 \\
\hline$\left(N V R_{t}-N V R_{t-1}\right) *$ Denver, $C O$ & 1.535 & 4.44 \\
\hline$\left(N \cup R_{t}-N V R_{t-1}\right) *$ Detroit, $M I$ & 0.503 & 1.46 \\
\hline$\left(N V R_{t}-N V R_{t-1}\right) *$ Fort Lauderdale, FL & 1.748 & 5.06 \\
\hline$\left(N V R_{t}-N V R_{t-1}\right) *$ Fort Fort-Arlington, $\mathrm{DX}$ & 1.168 & 3.38 \\
\hline$\left(N V R_{t}-N V R_{t-1}\right) *$ Greenville-Spartanburg-Anderson, SC & 0.133 & 0.39 \\
\hline$\left(N V R_{t}-N V R_{t-1}\right) *$ Hartford, $C T$ & 0.025 & 0.07 \\
\hline$\left(N V R_{t}-N V R_{t-1}\right) *$ Honolulu, $\mathrm{HI}$ & -0.158 & -0.46 \\
\hline$\left(N V R_{t}-N V R_{t-1}\right) *$ Houston, $T X$ & 2.162 & 6.25 \\
\hline$\left(N V R_{t}-N V R_{t-1}\right) *$ Indianapolis, IN & 1.052 & 3.04 \\
\hline$\left(N V R_{t}-N V R_{t-1}\right) *$ Jacksonville, FL & 1.731 & 5.01 \\
\hline$\left(N V R_{t}-N V R_{t-1}\right) *$ Kansas City, MO-KS & 0.392 & 1.13 \\
\hline$\left(N V R_{t}-N V R_{t-1}\right) *$ Los Angeles-Long Beach, CA & 1.575 & 4.56 \\
\hline$\left(N V R_{t}-N V R_{t-1}\right) *$ Miami, FL & 1.207 & 3.49 \\
\hline$\left(N V R_{t}-N V R_{t-1}\right) *$ Milwaukee-Waukesha, WI & 0.139 & 0.40 \\
\hline$\left(N V R_{t}-N V R_{t-1}\right) *$ Minneapolis-St. Paul, MN-W/I & 0.565 & 1.63 \\
\hline$\left(N V R_{\mathrm{r}}-N V R_{t-1}\right) *$ Nashville, TN & 1.126 & 3.25 \\
\hline$\left(N \cup R_{t}-N V R_{t-1}\right) *$ Nassau-Suffolk, NY & 0.013 & 0.04 \\
\hline$\left(N V R_{t}-N V R_{t-1}\right) *$ New Orleans, LA & 2.011 & 5.82 \\
\hline$\left(N \cup R_{t}-N V R_{t-1}\right) *$ Oakland, CA & 1.107 & 3.20 \\
\hline$\left(N V R_{t}-N V R_{t-1}\right) *$ Oklahoma City, OK & 1.296 & 3.75 \\
\hline$\left(N V R_{t}-N V R_{t-1}\right) *$ Orange County, CA & 0.659 & 1.91 \\
\hline$\left(N V R_{t}-N V R_{t-1}\right) *$ Orlando, $\mathrm{FL}$ & 1.257 & 3.64 \\
\hline$\left(N V R_{t}-N V R_{t-1}\right) *$ Philadelphia, PA-NJ & 0.430 & 1.24 \\
\hline$\left(N V R_{t}-N V R_{t-1}\right) *$ Phoenix-Mesa, $A Z$ & 0.640 & 1.85 \\
\hline$\left(N \vee R_{t}-N V R_{t-1}\right) *$ Pittsburgh, PA & 0.524 & 1.52 \\
\hline$\left(N R_{t}-N V R_{t-1}\right) *$ Portland-Vancouver, OR-W/A & 0.623 & 1.80 \\
\hline$\left(N V R_{t}-N V R_{t-1}\right) *$ Raleigh-Durham-Chapel Hill, NC & 0.506 & 1.46 \\
\hline$\left(N V R_{t}-N V R_{t-1}\right) *$ Richmond-Petersburg, VA & 1.040 & 3.01 \\
\hline$\left(N V R_{t}-N V R_{t-1}\right) *$ Sacramento, CA & 1.032 & 2.99 \\
\hline$\left(N V R_{t}-N V R_{t-1}\right) *$ St. Louis, MO-IL & 0.629 & 1.82 \\
\hline$\left(N V R_{t}-N V R_{t-1}\right) *$ San Antonio, $T X$ & 1.697 & 4.91 \\
\hline$\left(N V R_{t}-N V R_{t-1}\right) *$ San Diego, $C A$ & 1.142 & 3.30 \\
\hline$\left(N V R_{t}-N V R_{t-1}\right) *$ San Francisco, CA & 0.559 & 1.62 \\
\hline$\left(N V R_{t}-N V R_{t-1}\right) *$ San Jose, CA & 0.829 & 2.40 \\
\hline$\left(N V R_{t}-N V R_{t-1}\right) *$ Seattle-Bellevue-Everett, WA & 0.497 & 1.44 \\
\hline$\left(N V R_{t}-N V R_{t-1}\right) *$ Tampa-St. Petersburg-Clearwater, FL & 1.446 & 4.18 \\
\hline$\left(N V R_{\mathrm{t}}-N V R_{t-1}\right) *$ Tulsa, OK & 0.183 & 0.53 \\
\hline$\left(N V R_{t}-N V R_{t-1}\right) *$ West Palm Beach-Boca Raton, FL & 1.505 & 4.35 \\
\hline MSA (Group Effects) & & 0.24 \\
\hline F-Value (Separate Slopes) & & 10.23 \\
\hline$R^{2}$ & & 0.16 \\
\hline Model F-Value & & 5.30 \\
\hline
\end{tabular}

Note: Structural variables for MSAs are not reported in the table to conserve space. None are statistically significant at 0.10 or higher. 
By contrast, our results based on retail vacancy data indicate that the use of time structural variables in this context results in regression coefficients that are very difficult, if not impossible, to interpret due to excessive collinearity.

The magnitude of the spatial autoregressive parameters not only identifies the existence of spatial autocorrelation, but it is also consistent with the statistical significance of the MSA structural variables reported in Exhibit 4. The problem of isolating the effects of the NVR on LVRs, however, is difficult given the existence of both temporal and spatial autocorrelation. As shown in the next section, however, the extent to which NVRs influence LVRs is more easily examined when focusing on changes rather than levels of vacancy rates.

\section{First Differences}

The regression results in Exhibit 4 suggest that both national and local effects are important in explaining LVRs; Exhibit 5 results are not conclusive given multicollinearity in regressions that include time variables. Another perspective for assessing national versus local influence is focusing on explaining changes in LVRs; that is, to what extent do changes in NVRs influence changes in LVRs? Exhibit 6 reports the first-differences regressions similar to Equation (3), but using a common slope for the lagged change in NVR for all MSAs.

The results indicate negligible temporal autocorrelation and undetectable spatial autocorrelation. Moreover, the time MSA structural variables have a statistically insignificant $F$-value of 0.26 , and the lagged change in NVR variables are not statistically significant in explaining the variation of current LVRs changes. The NVR coefficient maintains a stable value of about 0.95 in all regressions. Therefore, regression results using first differences suffer from far fewer temporal and spatial autocorrelation problems than those using levels of vacancy rates.

These results suggest that the changes in vacancy rates are largely independent of a particular MSA. In addition, the changes in LVRs appear to have minimal correlation over time. And only contemporary changes (and not historical changes) in the
NVR influences LVRs. These results suggest that, over the time period studied, changes in vacancy rates do not show a perceptible positive or negative pattern that differs systematically by local market or over time. However, changes in LVRs appear strongly related to changes in NVRs.

One cannot conclude, however, that the influence of changes in the NVR is equivalent across MSAs. Exhibit 7 reports the findings of the impact of the NVR on each local MSA assuming a fixed-effects model with separate slopes for each MSA. The group effects (MSA structural variables) are not statistically significant; however, the interaction of $N V R_{t}-N V R_{t-1}$ and the MSA structural variables reveal statistically significant separate slopes.

Our findings indicate a great disparity of how LVRs change relative to changes in the NVR. On average, metropolitan areas in Texas, Florida and Louisiana are more sensitive to changes in the NVR than are many cities in the Northeast. One explanation is that local retail vacancy rates are highly susceptible to demand and supply conditions in the tourism and oil exploration industries; these industries tend to be highly cyclical. It is clear, however, that the near one-to-one correspondence between the NVRs and LVRs reported earlier does not capture the full extent of the diversity of responsiveness of the individual MSAs to changes in the NVR.

\section{Conclusion}

The purpose of this study was to investigate the relative extent to which LVRs in retail markets are influenced by local and national conditions. Using various regression models incorporating adjustments for fixed-effects, spatial and temporal influences, the results indicate that the variation in LVRs is considerable among the forty-six MSAs examined. LVRs in retail markets also appear to be highly correlated over time as well as spatially correlated with vacancy rates in surrounding MSAs. Our findings support those of Hanink (1996) that the levels of LVRs in surrounding MSAs are an important influence on the vacancy rate levels in neighboring MSAs; however, we also find that changes in NVRs are an important influence on 
changes in LVRs. We find further that the nature and extent of the influence of the NVR on LVR is not constant across markets, but is statistically different among MSAs.

The significance of the national rate in the models we estimate suggests that local retail real estate markets exhibit a high degree of correlation, which lessens the gains from regional diversification strategies. However, we also find that local markets are not perfectly correlated and that many exhibit substantial independence from national trends. Further, local markets tend to exhibit strong spatial correlation with their nearest neighbors. Thus, our findings support the use of regional portfolio diversification strategies in the effort to reduce unsystematic risk associated with investment in retail real estate.

\section{Endnotes}

1. Graff (1998) suggests that the risk reduction benefits reported in these studies may have been overestimated because the data were not adjusted for serial dependence and seasonal effects.

2. Time indicator variables are excluded in this regression to measure time-series autocorrelation.

3. More complicated autocorrelation structures were examined such as $\mathrm{AR}(2)$. However, while all MSAs had statistically significant AR(1) autocorrelation coefficients, the higher-order autocorrelation coefficients were most often statistically insignificant.

4. This model includes a spatially lagged dependent variable.

5. The empirical results of both the SAR and autoregressive response model are reported. The estimates for $\rho^{s}$ and the NVR coefficient are very similar for both specifications.

6. A contemporaneous relationship between the NVR is anticipated; however, the NVR may influence subsequent LVRs. Therefore, we also test a model with lagged NVRs.

7. Note that the first term will drop from the equation in empirical testing because slopes for all the MSAs will be present in the model, and the inclusion of the first term creates a singular matrix.
8. The Cochrane-Orcutt procedure involves estimating the time-series autocorrelation coefficient $\rho_{i}^{T}$ for each MSA $i$, then using these estimated coefficients to transform the data; the new estimated are free from the effects of firstorder time-series autocorrelation.

9. We are indebted to Kelley Pace for providing us with the Spatial Statistics Toolbox 1.0 software that was used for the spatial regressions, and for his discussions relating spatial statistics to our vacancy model.

10. Although not reported, we examined a fixed-effects regression, which included structural MSA variables. As anticipated, the MSA structural variables capture the effects of spatial autocorrelation, and the spatial autocorrelation coefficient is approximately zero.

11. The authors thank D. Hanink for his conversations concerning spatial modeling.

\section{References}

DiPasquale, D. and W. C. Wheaton, Urban Economics and Real Estate Markets, Englewood Cliffs, NJ: Prentice Hall, 1996.

Eppli, M. J., J. D. Shilling and K. D. Vandell, What Moves Retail Property Returns at the Metropolitan Level? Mimeo, 1996.

Graff, R. A., The Impact of Seasonality on Investment Statistics Derived from Quarterly Returns, Journal of Real Estate Portfolio Management, 1998, 4:1, 1-16.

Greene, W. H., Econometric Analysis, Third edition, Upper Saddle River, NJ: Prentice Hall, 1997.

Griffith, D. A., Spatial Regression Analysis on the PC: Spatial Statistics Using SAS, American Association of Geographers: Washington, DC, 1993.

Hanink, D. M., How "Local" are Local Office Markets? Real Estate Economics, 1996, 24:3, 341-58.

Hartzell, D. J., D. G. Shulman and C. H. Wurtzebach, Refining the Analysis of Regional Diversification for Income-Producing Real Estate, Journal of Real Estate Research, 1987, 2:2, 85-95.

Malizia, E. E. and R. A. Simons, Comparing Regional Classifications for Real Estate Portfolio Diversification, Journal of Real Estate Research, 1991, 6:1, 53-68.

Mueller, G. R., Refining Economic Diversification for Real Estate Portfolios, Journal of Real Estate Research, 1993, 8:1, 5568.

Pace, R. K., Performing large Spatial regressions and Autoregressions, Economics Letters, 1998, 54:3, 283-91. 